\title{
Preliminary Colorimetric Assessment of Progressive Nonsegmental Vitiligo under Short-Term Intravenous Methylprednisolone Pulse Therapy
}

\author{
Yuiko Nagata*, Atsushi Tanemura*, Emi Ono, Aya Tanaka, Kenichi Kato, Mizuho Yamada, \\ Ichiro Katayama \\ Department of Dermatology, Integrated Medicine Osaka University Graduate School of Medicine, Suita, Japan \\ Email: tanemura@derma.med.osaka-u.ac.jp
}

Received 6 March 2014; revised 5 April 2014; accepted 12 April 2014

Copyright (C) 2014 by authors and Scientific Research Publishing Inc.

This work is licensed under the Creative Commons Attribution International License (CC BY).

http://creativecommons.org/licenses/by/4.0/

(c) (i) Open Access

\begin{abstract}
Although the administration of systemic steroid for nonsegmental vitiligo in the progressive stage is a recommended treatment according to guidelines, the clinical efficacy of this regimen has not been fully established. In this study, we evaluated the clinical efficacy of half-dose steroid treatment and stratified the evidence regarding its usefulness in progressive vitiligo patients. Half-dose steroid pulse therapy $(500 \mathrm{mg} /$ day of methylprednisolone for three sequential days) was administered intravenously three times monthly in five vitiligo patients. The visual changes in vitiligo lesions were evaluated on photographs and quantified using a spectrophotometer. As results, all patients completed three cycles of treatment without severe adverse events. Three of the five patients achieved disease arrest with decrease in white contrast. Therefore, short-term and halfdose steroid therapy is well tolerated and effective for achieving disease arrest in progressive nonsegmental vitiligo. The whiteness assessed by a spectrophotometer is possibly associated with therapeutic response to steroid therapy.
\end{abstract}

\section{Keywords}

Intravenous Methylprednisolone Pulse Therapy, Progressive Nonsegmental Vitiligo, Spectrophotometer

\footnotetext{
${ }^{*}$ These authors are equally contributed to this study.

How to cite this paper: Nagata, Y., et al. (2014) Preliminary Colorimetric Assessment of Progressive Nonsegmental Vitiligo under Short-Term Intravenous Methylprednisolone Pulse Therapy. Journal of Cosmetics, Dermatological Sciences and Applications, 4, 135-140. http://dx.doi.org/10.4236/icdsa.2014.43019
} 


\section{Introduction}

The recommended treatment for nonsegmental vitiligo vulgaris includes topical ointments of steroids and tacrolimus, ultraviolet phototherapy, systemic steroids and surgery according to international guidelines [1] [2].

Ultraviolet light therapy such as narrow band UVB has been considered to be the most common modalities in treating cases of disseminated vitiligo. However, narrow band UVB irradiation requires consultations once or twice a week and is mostly refractory in advanced and/or long-lasting cases. Steroid therapy for advanced vitiligo recommended as a class C1 treatment in one set of guidelines [2] is known as fairly effective and has two routes of administration, namely, oral and intravenous. Although oral steroid therapy suggested by Radakovic [3], Kim [4], and Pasricha [5], unacceptable side effects (moon face, exacerbation of diabetes mellitus and hypertension, and so on) were observed in $50 \%$ or more of patients due to the long-term administration period. Meanwhile, with respect to intravenous steroid pulse therapy, Seiter obtained disease improvements in pathology in $90 \%$ of cases with temporary and reversible side effects [6].

In this preliminary study, we evaluated a therapeutic effect of half-dose methylprednisolone pulse therapy for patients with progressive nonsegmental vitiligo based on ocular inspection and unique objective calculation of white contrast and redness and supposed the future position of this treatment on guidelines in reference with previous literatures.

\section{Methods}

Five nonsegmental vitiligo patients in a state of progression were enrolled in this study; their demographic characteristics are summarized in Table 1 . All patients had noticed lesion enlargement with no improvement six months before their first visit.

\section{Quantitative Evaluation of Color Changes}

We used a spectrophotometer, an apparatus used to digitize three elements of color: hue (color, such as red, blue, etc.), brightness (degree of brightness) and chroma (degree of saturation). The L, a, and b scores represent skin whiteness, erythematous changes and bluntness, respectively. The delta L score represents a white contrast as difference of the degree between lesional minus perilesional skin. The target lesions were arbitrarily assigned for assessment, and the color scores were calculated using a spectrophotometer for an objective color evaluation (CD-2600d, Konica Minorta, Japan) both before and after treatment. The assigned sites did not change throughout the study. The mean of three calculated scores was used as representative data.

The paired $t$-test was used for the analysis of differences in color tone before and after treatment. A value of $\mathrm{p}$ $<0.05$ (two-tailed) was considered to be statistically significant. All statistical analyses were performed using the Prism software program, version 5 (GraphPad Software Inc., La Jolla, CA, USA).

\section{Cases and Results}

\section{Representative Case}

A 62-year-old Japanese female noticed depigmented macules on her frontal chest four years ago and subsequently suffered from progressive depigmentation on the buttock and lower extremities as well as perilesional hyperpigmentation, regardless of treatment with narrowband UVB phototherapy. A screening examination did not detect any complications associated with nonsegmental vitiligo treatment that are expected to be exacerbated by the use of systemic steroids, such as infective disease, hypertension or diabetes mellitus. After the first cycle of steroid half-pulse therapy, most of the depigmented macules became blurred and stopped expanding. After the third cycle of therapy, the depigmented lesions, particularly those on the cubital fossa and lower extremities, decreased in size (Figure 1(a)). No exacerbation or recurrence of the lesions were detected for 12 months after the three cycles of half-pulse therapy, and the patient felt good about clinical outcome in the series of half-pulse therapy treatments.

In this study, each lesion was compared using routine photographs of the whole body. Three of the five patients achieved disease arrest. One patient exhibited enlargement of the lesions, particularly on the lower extremities. As to adverse events, a slight increase in the white blood cell count and temporal insomnia were noted in three and two patients, respectively. The trend of delta L scores before and after treatment was significantly 
Table 1. Patients’ demographics and disease outcome.

\begin{tabular}{|c|c|c|c|c|c|c|c|c|c|c|c|c|}
\hline \multirow[b]{2}{*}{ Patient } & \multicolumn{5}{|c|}{ Patient' characteristics } & \multicolumn{7}{|c|}{ Disease outcome after intervention } \\
\hline & $\begin{array}{l}\text { Age } \\
\text { (years) }\end{array}$ & Sex & $\begin{array}{l}\text { Duration } \\
\text { of disease } \\
\text { (years) }\end{array}$ & $\begin{array}{l}\text { Treatment } \\
\text { history }\end{array}$ & Complications & $\begin{array}{c}\text { Period of } \\
\text { intervention }\end{array}$ & $\begin{array}{l}\text { Disease } \\
\text { arrest }\end{array}$ & $\begin{array}{l}\text { Boarder } \\
\text { blurring }\end{array}$ & Repigmentation & Assinged site & $\begin{array}{l}\text { Adverse } \\
\text { effect }\end{array}$ & $\begin{array}{l}\text { Period of } \\
\text { follow up }\end{array}$ \\
\hline 1 & 68 & M & 20 & $\begin{array}{l}\text { Topical } \\
\text { corticosteroid } \\
\text { vitamin } D_{3}\end{array}$ & N.P. & Aug. to Mar. & No & No & No & Back of neck & N.P. & $\begin{array}{c}1 \text { year } \\
4 \text { months }\end{array}$ \\
\hline 2 & 17 & M & 5 & $\begin{array}{l}\text { Topical } \\
\text { corticosteroid } \\
\text { tacrolimus } \\
\text { vitamin } \mathrm{D}_{3}\end{array}$ & N.P. & Aug. to Apr. & No & No & $\begin{array}{l}\text { Follicular } \\
\text { repigmentation } \\
\text { but recurrented }\end{array}$ & $\begin{array}{l}\text { Left forearm, } \\
\text { right lower leg }\end{array}$ & N.P. & $\begin{array}{c}1 \text { year } \\
4 \text { months }\end{array}$ \\
\hline 3 & 71 & $\mathrm{~F}$ & 35 & $\begin{array}{l}\text { Topical } \\
\text { corticosteroid } \\
\text { vitamin } \mathrm{D}_{3} \text { oral } \\
\text { corticosteroid }\end{array}$ & $\begin{array}{l}\text { Sjögren's } \\
\text { syndrome }\end{array}$ & Dec. to Mar. & Yes & Yes & $\begin{array}{l}\text { Peripheral } \\
\text { repigmentation }\end{array}$ & $\begin{array}{l}\text { Each cheek, } \\
\text { fprehead }\end{array}$ & $\begin{array}{l}\text { Temporal } \\
\text { insomnia }\end{array}$ & $\begin{array}{c}1 \text { year } \\
3 \text { months }\end{array}$ \\
\hline 4 & 71 & M & 2 & $\begin{array}{l}\text { Topical } \\
\text { corticosteroid } \\
\text { vitamin } \mathrm{D}_{3} \mathrm{UV}\end{array}$ & N.P. & Nov. to Jan. & Yes & Yes & $\begin{array}{l}\text { Peripheral } \\
\text { repigmentation }\end{array}$ & $\begin{array}{l}\text { Left lower abdomen, } \\
\text { left lower leg }\end{array}$ & $\begin{array}{l}\text { Temporal } \\
\text { insomnia }\end{array}$ & $\begin{array}{l}1 \text { year } \\
4 \text { months }\end{array}$ \\
\hline 5 & 64 & $\mathrm{~F}$ & 4 & $\begin{array}{l}\text { Topical } \\
\text { corticosteroid } \\
\text { UV }\end{array}$ & N.P. & Apr. to Jan. & Yes & Excellent & $\begin{array}{l}\text { Peripheral } \\
\text { repigmentation }\end{array}$ & $\begin{array}{l}\text { Back of neck, } \\
\text { anterior chest }\end{array}$ & $\begin{array}{l}\text { Temporal } \\
\text { insomnia }\end{array}$ & $\begin{array}{c}2 \text { year } \\
3 \text { month }\end{array}$ \\
\hline
\end{tabular}

N.P.: not particular.

separated between the patients with and without disease arrest (Figure 1(b)). Once the a score tended to increase in all patients after study, maybe reflecting on steroid-induced telangiectasia, each p-value of the a or b score was not significant (Figure 1(c); the b scores not shown).

\section{Discussion}

Short term intravenous steroid half-pulse therapy was applied in five progressive nonsegmental vitiligo patients refractory to other treatments, and disease arrest and/or slurred lesions were observed in three of the five patients. It is very important to inhibit disease progression in cases of nonsegmental vitiligo in the progressive stage because, once they develop, vitiligo lesions are difficult to cure. Although we were unable to measure the exact percentage of lesions with repigmentation in the patients with lesion obscureness, the outcomes were highly valued by the patients due to the remarkable improvement in their appearance. No severe adverse events were observed for at least six months after the initial treatment, except for temporary insomnia. In the present study, there was high number of lesions in which the border was notably altered to be more obscure; therefore, most patients reported being satisfied with the treatment outcomes.

The efficacy of short-term systemic steroid therapy is supported by growing evidence as well as the results of the present study and previous publications [3]-[9]. Seiter et al. applied treatment with $8 \mathrm{mg} / \mathrm{kg}$ body weight of steroids three times for three consecutive days, similar to our regimen, and observed a rate of repigmentation of 71\% among patients with progressive vitiligo, whereas no improvements were noted in those with stable vitiligo [6]. In contrast, a long-term oral steroid regimen comprising the administration of $10 \mathrm{mg}$ of dexamethasone for two days followed by five days off for 24 weeks has also been found to be effective for achieving disease arrest, although mild to moderate side effects were reported in $69 \%$ of patients [4]. In addition, combination therapy consisting of high-dose intravenous prednisolone and PUVA has been shown to be highly effective in treating patients with generalized vitiligo [9]. It is conceivable that short-term treatment induces less frequent and milder adverse events than the long-term administration of steroid.

We used a spectrophotometer to measure the color changes determined according to the Lab score before and after the administration of steroid therapy. The device was useful to calculate the white contrast when we compared therapeutic effect between narrowband UVB and sun irradiation in addition to topical tacalcitol [10]. The delta L score exhibited a tendency to decrease after treatment in the patients who achieved disease arrest not disease progression or recurrence, as expected. However, sun exposure on measurement and seasonal changes both of which can affect the scores should be considered to prevent data deviation and variation.

Corticosteroids are known to enhance melanogenesis in an endogenous and/or exogenous manner [11] [12]. In murine melanoma cell lines, diethylstilbestrol induces melanin synthesis via the activation of the cAMP-PKA signaling pathway followed by the upregulation of tyrosinase and MITF [11]. In general, corticosteroids bind to 

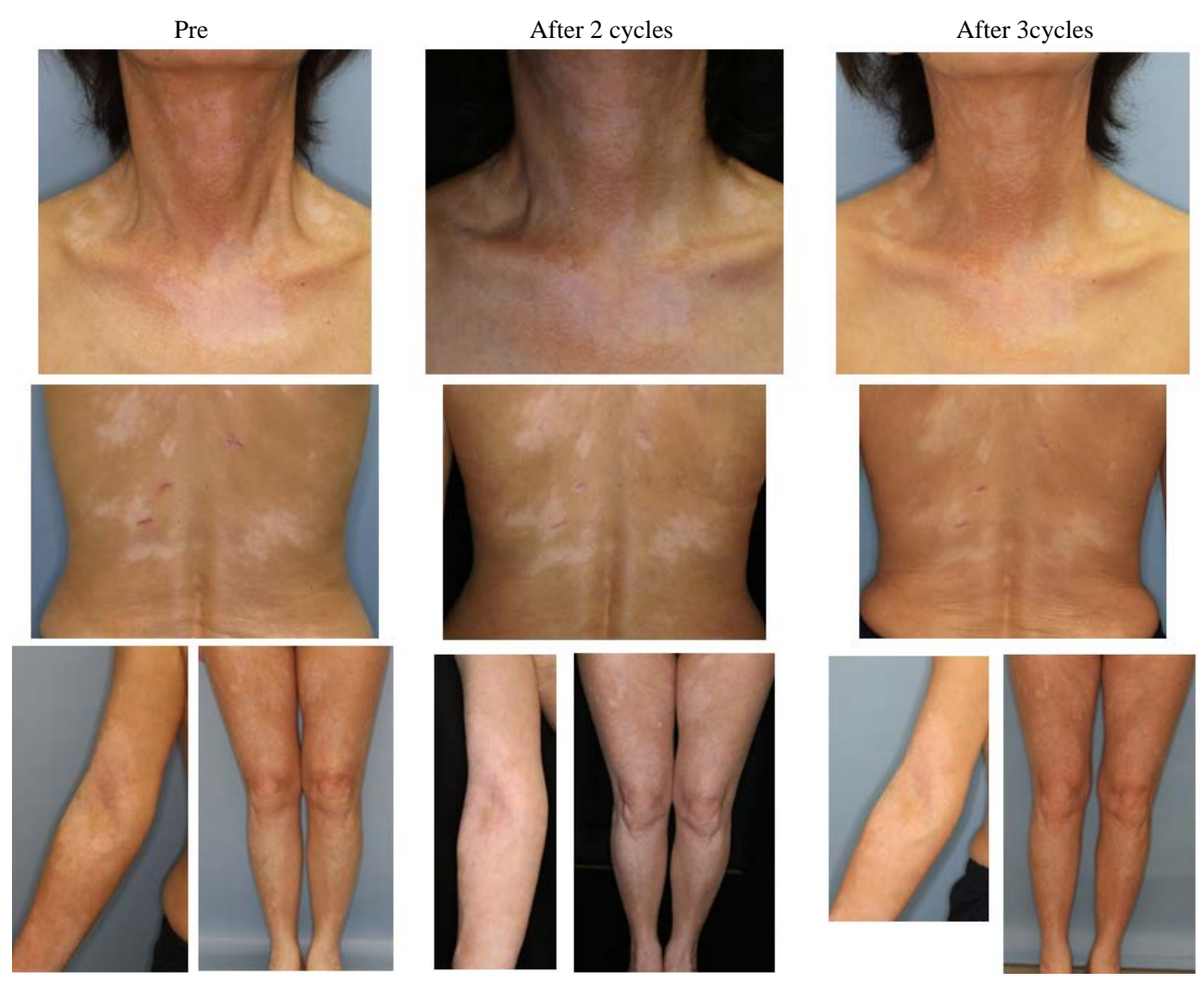

(a)

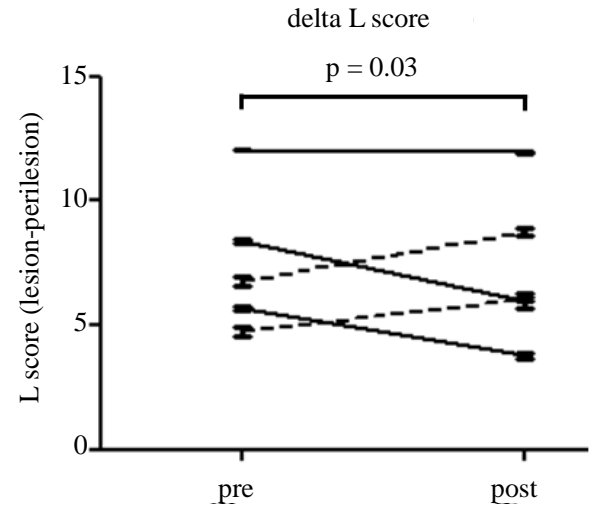

(b)

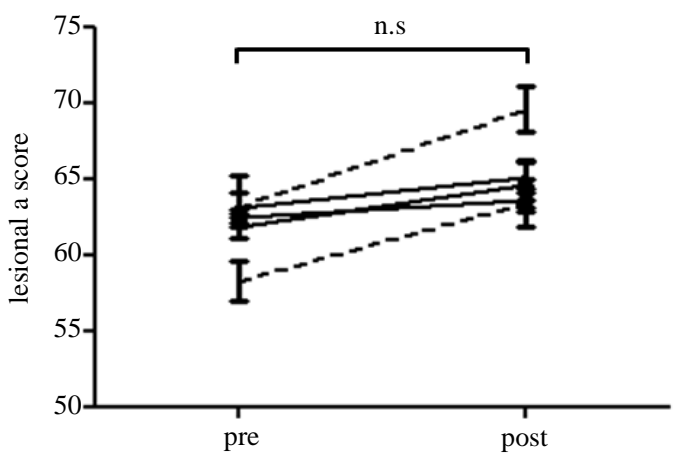

(c)

Figure 1. (a) Clinical appearance of a representative case before (left) and after 2 (middle) and 3 cycles (right) of half-pulse therapy. The views of front neck, middle back, and extremities are placed on upper, middle, and lower panels, respectively; (b) The change of delta L score before and after treatment was compared between the patients with and without disease arrest. The score change on lesions with and without disease arrest are shown by a solid and dotty lines, respectively. Notably, decrease in delta $\mathrm{L}$ score was more evident in patients with disease arrest, indicating that the change of delta L score reflected on therapeutic response; (c) The change of a score before and after treatment was compared between patients with and without disease arrest.

their receptors, thus forming a homodimer, and move into the nucleus where they upregulate the expression of MITF and downregulate the expression of inflammatory cytokines, such as IL-1, 2, 6 and TNF- $\alpha$ transcription factors [12]. A decreased cytokine expression can inhibit lymphocyte infiltration in the skin. In view of physiological effects of corticosteroids on melanogenesis and inflammation, it is believed that systemic corticosteroid therapy is valuable for treating vitiligo patients without complete melanocyte loss. 
In this preliminary study, we applied a spectrophotometer to measure color changes and quantify the improvements in the vitiligo lesions. However, the $\mathrm{L}$ and delta $\mathrm{L}$ scores did not significantly decrease, even in the patients with diffuse repigmentation, as described in the representative case. The side effects of short-term treatment were minimal compared to that of long-term, low-dose oral steroids, which can induce osteoporosis, hypertension and increased carbohydrate tolerance.

\section{Conclusion}

In conclusion, we administered the short-term mini-pulse steroid therapy in patients with progressive nonsegmental vitiligo and evaluated the effectiveness of this regimen in achieving repigmentation and improving color contrast based on both ocular inspection and the results of a spectrometer. More than $50 \%$ of the patients achieved disease arrest and obscureness, with a high social value on the final appearance. The delta L score is an objective parameter of lesion whiteness and improvements in disease severity. In view of current stratified data, including that presented in the current study, the administration of systemic steroids instead of phototherapy should be considered in patients with progressive nonsegmental vitiligo in early stage. Further controlled studies with large numbers of patients and variety in the treatment regimen are needed to establish the proper position and line in the treatment algorithm for this disease.

\section{Conflicts of Interest}

None.

\section{References}

[1] Taieb, A., Alomar, A., Bohm, M., Dell’Anna, M.L., De Pase, A., Elefttheriadou, V., Ezzedine, K., Gauthier, Y., Gawkrodger, D.J., Jouary, T., Leone, G., Moretti, S., Nieuweboer-Krobotova, L., Olsson, M.J., Parsad, D., Passeron, T., Tanew, A., van der Veen, W., van Geel, N., Whitton, M., Wolkerstorfer, A. and Picardo, M. (2013) Guidelines for the Management of Vitiligo: The European Dermatology Forum Consensus. British Journal of Dermatology, 168, 5-19. http://dx.doi.org/10.1111/j.1365-2133.2012.11197.x

[2] Oiso, N., Suzuki, T., Wataya-Kaneda, M., Tanemura, A., Tanioka, M., Fujimoto, T., Fukai, K., Kawakami, T., Tsukamoto, K., Yamaguchi, Y., Sano, S., Mitsuhashi, Y., Nishigori, C., Morita, A., Nakagawa, H., Mizoguchi, M. and Katayama, I. (2013) Guidelines for the Diagnosis and Treatment of Vitiligo in Japan. Journal of Dermatology, 40, 1-11. http://dx.doi.org/10.1111/1346-8138.12099

[3] Radakovic-Fijan, S., Fürnsinn-Friedl, A.M., Hönigsmann, H. and Tanew, A. (2001) Oral Dexamethasone Pulse Treatment for Vitiligo. Journal of American Academy of Dermatology, 44, 814-817. http://dx.doi.org/10.1067/mjd.2001.113475

[4] Kim, S.M., Lee, H.S. and Hann, S.K. (1999) The Efficacy of Low-Dose Oral Corticosteroids in the Treatment of Vitiligo Patients. International Journal of Dermatology, 38, 546-550. http://dx.doi.org/10.1046/j.1365-4362.1999.00623.x

[5] Pasricha, J.S. and Khaitan, B.K. (1993) Oral Mini-Pulse Therapy with Betamethasone in Vitiligo Patients Having Extensive or Fast-Spreading Disease. International Journal of Dermatology, 32, 753-757. http://dx.doi.org/10.1111/j.1365-4362.1993.tb02754.X

[6] Seiter, S., Ugurel, S., Tilgen, W. and Reinhold, U. (2000) Use of High-Dose Methylprednisolone Pulse Therapy in Patients with Progressive and Stable Vitiligo. International Journal of Dermatology, 39, 624-627. http://dx.doi.org/10.1046/j.1365-4362.2000.00006.x

[7] Hertz, K.C., Gazze, L.A., Kirkpatrick, C.H. and Katz, S.I. (1977) Autoimmune Vitiligo: Detection of Antibodies to Melanin-Producing Cells. New England Journal of Medicine, 297, 634-637. http://dx.doi.org/10.1056/NEJM197709222971204

[8] Barret, D.F. and Lee, H.A. (1982) Corticosteroid Pulse Therapy in Dermatology. British Journal of Dermatology, 107, 31.

[9] Lee, Y., Seo, Y.J., Lee, J.H. and Park, J.K. (2007) High-Dose Prednisolone and Psoralen Ultraviolet A Combination Therapy in 36 Patients with Vitiligo. Clinical and Experimental Dermatology, 32, 499-501. http://dx.doi.org/10.1111/j.1365-2230.2007.02387.x

[10] Tanemura, A., Takahashi, A., Ueki, Y., Murota, H., Yamaguchi, Y. and Katayama, I. (2012) Therapeutic Comparison between Sun Irradiation vs. Narrowband UVB Phototherapy along with Topical Tacalcitol for Vitiligo Vulgaris. Journal of Cosmetics, Dermatological Sciences and Applications, 2, 88-91. http://dx.doi.org/10.4236/jcdsa.2012.22020

[11] Jian, D., Jiang, D., Su, J., Chen, W., Hu, X., Kuang, Y., Xie, H., Li, J. and Chen, X. (2011) Diethylstilbestrol Enhances 
Melanogenesis via cAMP-PKA-Mediating Up-Regulation of Tyrosinase and MITF in Mouse B16 Melanoma Cells. Steroids, 76, 1297-1304. http://dx.doi.org/10.1016/j.steroids.2011.06.008

[12] Birlea, S.A., Costin, G.E. and Norris, D.A. (2009) New Insights on Therapy with Vitamin D Analogs Targeting the Intracellular Pathways That Control Repigmentation in Human Vitiligo. Medicinal Research Reviews, 29, 514-546. http://dx.doi.org/10.1002/med.20146 